\title{
EFFECT OF OVERCONSOLIDATION AND ANISOTROPY OF KAOLIN CLAY USING TRUE TRIAXIAL TESTING
}

\author{
Amit Prashanti) and Dayakar Penumadiii)
}

\begin{abstract}
A series of strain controlled undrained true triaxial tests on cubical specimens have been performed using a fully automated flexible boundary experimental setup, with real-time feedback control system to evaluate the three-dimensional mechanical behavior of kaolin clay. This paper concentrates on the comparative response of the soil elements under monotonic shear loading observed at various overconsolidation levels. A possible shape of the initial yield surface is explored based on the limit of purely elastic deformations. The discussion includes the influence of the relative magnitudes of principal stresses on the clay behavior observed at different overconsolidation ratio values. Failure conditions are shown to be governed by the onset of localizations developed within the specimens, and because of which the specimens show sudden failure response before reaching a perfectly plastic deformation conditions. A reference surface constraining the ultimate plastic yielding of clay is found to be different from the observed failure surface. Based on the experimental observations, a 3-D failure criterion is developed that grows in size as a function of pre-consolidation stress.
\end{abstract}

Key words: localization, overconsolidated clays, shear deformation, strain, three-dimensional analysis, undrained shear tests, yielding (IGC: D5/D6)

\section{INTRODUCTION}

Cohesive frictional materials show complex mechanical behavior. The observed shear strength behavior depends on the size, shape, mineral composition and packing of the particles, the past stress history, the pore fluid, the magnitude and orientation of principal stresses during loading, rate of loading, and other factors. Single element laboratory tests were often used to characterize various aspects of the observed soil behavior, and the experimental data obtained was used to formulate constitutive equations (Roscoe and Burland, 1968; Schofield and Wroth, 1968; Prevost, 1981; Defalias, 1987; Lade, 1990; Whittle and Kavvadas, 1994; and many others). Laboratory tests in earlier studies for a comprehensive description of normally consolidated and overconsolidated clays (e.g., Henkel, 1959; Parry, 1960) often involved single axis loading conditions (e.g., triaxial compression testing). However, for better simulation of field conditions, the laboratory tests had to be designed to evaluate three-dimensional yield and failure behavior by subjecting a soil element to a true triaxial state of stress and strain. Early devices that were developed to perform these tests were cumbersome, difficult to operate and typically required manual control to perform experiments. Recent advances in control hardware and software have allowed high-speed closed loop control to be used in soil testing. This allows accurate and repeatable tests to be performed on the soil specimens. Shibata and Karube (1965), Broms and Casbarian (1965), Yong and McKyes (1971), Vaid and Campanella (1974), Saada and Bianchini (1975), Lade and Musante (1978), and Germaine (1982) took advantage of these technologies in parts and performed traditional triaxial, plane strain, axial-torsional and true triaxial tests. However, most of these studies were limited to the description of normally consolidated (NC) clay behavior and the primary discussion was about the influence of the changing magnitudes and directions of the principal stresses. For a complete description of the clay behavior, it is essential to perform similar studies at various overconsolidation ratio (OCR) values using the same testing apparatus. Use of same testing apparatus should eliminate the influence of specimen shape and boundary conditions on the observed relative response of the clay.

The objective of the current research is to evaluate the relative response of the three-dimensional mechanical behavior of normally consolidated (NC) to heavily overconsolidated $(\mathrm{OC})$ kaolin clay under flexible boundary conditions using a true triaxial device, which performs tests on a $102 \mathrm{~mm}$ cubical cohesive soil specimen. This testing system uses three-axis electro-pneumatic Propor-

i) Research Assistant, Dept. of Civil and Environmental Engineering, University of Tennessee, Knoxville, Tennessee, USA (aprashan@ utk.edu).

ii) Associate Professor, ditto (dpenumad@utk.edu).

The manuscript for this paper was received for review on June 7, 2004; approved on January $18,2005$.

Written discussions on this paper should be submitted before January 1, 2006 to the Japanese Geotechnical Society, 4-38-2, Sengoku, Bunkyoku, Tokyo 112-0011, Japan. Upon request the closing date may be extended one month. 
Table 1. Properties of Kaolin Clay

\begin{tabular}{l|l}
\hline Liquid limit & $65 \%$ \\
\hline Plasticity index & $35 \%$ \\
\hline Specific gravity & 2.63 \\
\hline Percentage finer than $10 \mu \mathrm{m}$ & $92 \%$ \\
\hline Percentage finer than $2 \mu \mathrm{m}$ & $62 \%$ \\
\hline Activity & 0.44 \\
\hline
\end{tabular}

tional-Integral-Derivative (PID) control and applies three mutually perpendicular principal stresses on cubical soil specimens using flexible membranes. During true triaxial testing, three axes of the specimen were identified as $x, y$, and $z$-axis. Total stress values applied in each direction of cubical specimen were measured using pressure transducers. The normal stress was recorded in the three principal directions. Deformation was recorded on all six faces of the specimen using linear variable displacement transducer (LVDT), and the values along opposite faces were averaged to get the strain in three directions. Internal (inside the specimen) and external (at the boundary of specimen) pore pressures were measured using absolute-pressure-transducers.

\section{Soil Specimens Used for Testing}

Tests were performed on slurry-consolidated specimens of kaolin clay that were prepared in a slurry consolidometer with the square base of $102 \times 102 \mathrm{~mm}$ as described by Penumadu et al. (1998). During the specimen preparation, the slurry was consolidated to $207 \mathrm{kPa}$ effective vertical stress under $K_{0}$ condition and the direction of loading was marked as the $z$-axis of each specimen. As a result, the specimens were expected to have a certain degree of cross-anisotropy about the $z$-axis. The index properties of specimen soil are provided in Table 1. The influence of anisotropy on the consolidation behavior of clay was evaluated by performing two constant-rate-of-strain (CRS) tests. In one test, the axial load for $K_{0}$ consolidation was applied in the direction of initial slurry consolidation; whereas in the other test the axial load was perpendicular to it.

\section{PID Real-Time Feedback Control}

The algorithm of PID control is based on adjusting the output channel to match a target command using three terms: a proportional term $P$, an integral term $I$, and a differential term $D$.

$$
O(t)=P e(t)+I \int e\left(t^{\prime}\right) d t^{\prime}+D \frac{d e(t)}{d t}
$$

The $e(t)$ term in Eq. (1) represents the error term and is the difference between the target value and the input value at any instant of time. The PID algorithm minimizes this difference by adjusting the output value. The PID control loop updates all input variables every 20 milliseconds to reduce the $e(t)$ term to a small value quickly. Tuning of
$P, I$ and $D$ coefficients in PID algorithm (Perry, 1973) plays an important role in the observed stress-strain, pore pressure and strength behavior of clay.

\section{True Triaxial Testing}

In the first stage of testing, the specimens were assembled in the system and saturated using backpressure. Skempton's parameter $B$, obtained from the internal pore pressure measurements using a hypodermic needle during the saturation phase, agreed well with that obtained from the external pore pressure measurements. A minimum $B$-value of 0.98 was used as the criteria for ensuring full saturation. In second stage, the specimens were hydrostatically (isotropically) consolidated to 275 $\mathrm{kPa}$ resulting in $\mathrm{NC}$ cubical clay specimens and then isotropically unloaded to achieve a desired value of overconsolidation ratio (OCR). In the third stage, during undrained shearing, a strain rate of $0.05 \% / \mathrm{min}$ along $\sigma_{1}$-axis ( $z$-axis) was found suitable for present clay to ensure pore pressure equilibrium under undrained condition. Strain rate along $z$-axis was maintained at a constant value using PID real-time feedback control between the applied normal stress and corresponding axial deformation. In order to ensure a constant intermediate principal stress ratio $b$-value (Eq. (2)), the required $\sigma_{2}$ was generated along $y$-axis in a stress control mode using another PID feedback control.

$$
b=\frac{\sigma_{2}-\sigma_{3}}{\sigma_{1}-\sigma_{3}}
$$

The true triaxial tests were performed on the cubical specimens at various intermediate principal stress ratio, $b$-values ( $b=0,0.25,0.5,0.75$ and 1.0$)$. Keeping the same isotropic pre-consolidation stress value $(275 \mathrm{kPa})$, the tests were repeated for three OCR values, OCR $=1,5$ and 10. The observed stress-strain, pore pressure and strength behavior in a series of tests on moderately overconsolidated $(\mathrm{OCR}=5)$ kaolin clay was presented by Prashant and Penumadu (2004) and the results were discussed to evaluate the influence of the relative magnitude of intermediate principal stress $\left(\sigma_{2}\right)$ and the onset of localization. For other overconsolidation stages $(\mathrm{OCR} \gg 5$ or $\mathrm{OCR} \ll$ 5 ), the stress anisotropy might show significantly different mechanical response of clay. Results obtained from the series of tests performed at three overconsolidation stages, $\mathrm{OCR}=1,5$, and 10 are compared in this paper in order to deduce the variation in the influence of $\sigma_{2}$ at various overconsolidation stages. The influence of $\sigma_{2}$ for lightly overconsolidated clay may be assumed to be inbetween the observed behavior for normally consolidated $(\mathrm{OCR}=1)$ and moderately overconsolidated $(\mathrm{OCR}=5)$ clay. To complete the description of overconsolidated clay in triaxial plane, two additional triaxial compression $(b=0)$ tests were performed on the cubical specimens with lightly overconsolidated initial stress state i.e. with $\mathrm{OCR}=1.5$ and 2. Possible shapes of initial yield and failure surfaces in triaxial plane are explored based on the data obtained from $b=0$ tests performed at five different OCR values. 
Direction of slurry consolidation, z-axis

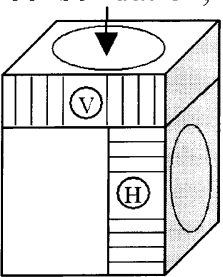

Axial load during

$\mathrm{K}_{\mathrm{o}}$ consolidation

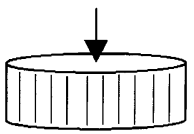

(a)

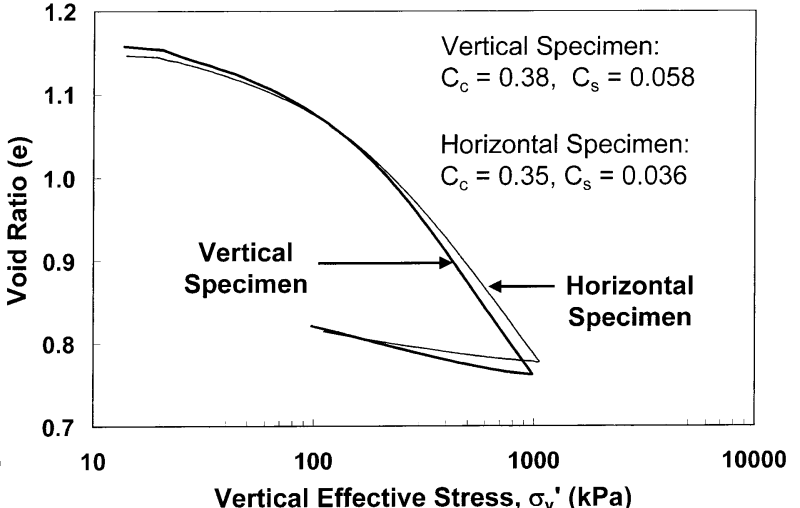

Fig. 1. Constant Rate of Strain (CRS) tests: (a) direction of $K_{0}$ consolidation and (b) consolidation curves, for vertical $V$ and horizontal $H$ specimens
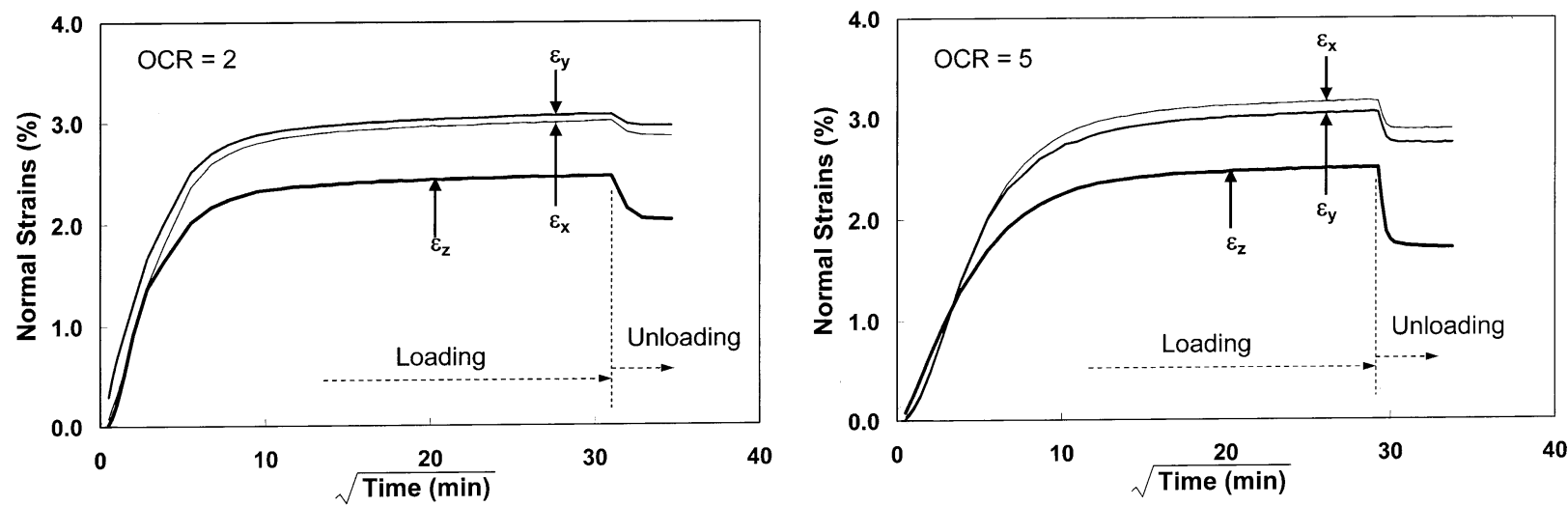

Fig. 2. Normal strain along three specimen axes during isotropic consolidation

\section{CONSOLIDATION BEHAVIOR OF CLAY}

In order to assess the influence of inherent anisotropy on the consolidation behavior of clay, constant-rate-ofstrain $K_{0}$ consolidation tests (CRS test, ASTM: D4186-89 1998) were performed by consolidating the specimens in two directions (Fig. 1). For the vertical consolidation, the direction of axial loading was along the $z$-axis; whereas for the horizontal consolidation, it was rotated by $90^{\circ}$ from the $z$-axis. These specimens were taken from a single cubical specimen as shown in Fig. 1(a). The specimens were consolidated to $1000 \mathrm{kPa}$ at the axial strain rate of $0.10 \% / \mathrm{min}$ and then unloaded to $100 \mathrm{kPa}$ at the strain rate of $0.04 \% / \mathrm{min}$. Figure 1 (b) shows the consolidation curves (void ratio vs vertical effective stress) obtained for two specimens. The compression index, $C_{\mathrm{C}}$, and the swelling index, $C_{\mathrm{S}}$, have been commonly used to characterize the volumetric deformation properties (compressibility) of clay, and, for isotropic material, these indices were assumed to be directionally independent. In several constitutive theories developed in the past, these indices were also used in some form to describe the stress path dependency of the shear stiffness and strength properties of clay. Due to anisotropic nature of the specimens used in this study, the compression and swelling indices obtained for the vertical specimen $\left(C_{C}=0.38, C_{\mathrm{S}}=0.058\right)$ were higher than those obtained for the horizontal specimen $\left(C_{C}=0.35, C_{S}=0.036\right)$ of the same clay. The recoverable deformation (elastic) property of clay, swelling index $C_{\mathrm{S}}$, was observed to be significantly different for the vertical and the horizontal specimen. The tests were repeated three times to ensure that the marked difference in $C_{\mathrm{C}}$ and $C_{\mathrm{S}}$ values was not a result of experimental scatter. The difference between the two indices, $\left(C_{\mathrm{C}}-C_{\mathrm{S}}\right)$, defines the permanent deformation (plastic) property of clay, which was observed to be a constant (0.32) for two types of the specimens. This observation leads to an argument that the relationship between the elastic component of volumetric deformation and the applied loading for an anisotropic clay material may not be directionally independent of the loading direction; however, for the plastic component, the relationship can be assumed to be directionally independent.

Using the true triaxial device, the cubical specimens were first isotropically consolidated to NC state at the mean effective stress $=275 \mathrm{kPa}$, and then isotropically unloaded to achieve desired OCR value. The direction of axial loading during specimen preparation, the axis of cross-anisotropy, was aligned with the $z$-axis of the true triaxial device. Figure 2 shows the individual normal strains measured along the $x, y$, and $z$-axis of specimen 
during consolidation stage of two of the tests presented in this paper: $\mathrm{OCR}=2$ and $\mathrm{OCR}=5$. Since $K_{0}<1$, the pre-consolidation stress corresponding to $x$ and $y$ axes was lower than that corresponding to $z$-axis. Due to symmetry about the axis of anisotropy ( $z$-axis), the normal strains developed along the $x$-axis were essentially the same as along the $y$-axis. During loading, the normal strain along the $z$-axis was lower, i.e. the specimen response was stiffer along $z$-axis, in comparison to the other two directions $\left(\max \varepsilon_{\mathrm{x}}-\varepsilon_{\mathrm{z}} \approx 0.5 \%\right.$ ). However, during unloading $\left(p^{\prime}=275 \rightarrow 138 \mathrm{kPa}\right.$ for $\mathrm{OCR}=2$, and $p^{\prime}=275 \rightarrow 55 \mathrm{kPa}$ for $\mathrm{OCR}=5$ ), this trend reversed and recovered normal strain along $z$-axis was much higher than that along the other two directions. Therefore, the material response to unloading was softer along $z$-axis in comparison to the response along $x$ - and $y$-axis. This behavior of specimen is consistent with the difference observed in $C_{\mathrm{S}}$ values for vertical and horizontal specimens during CRS testing.

\section{SHEAR FAILURE AND LOCALIZED DEFORMATIONS}

During the shear behavior analysis of undrained true triaxial test data, the failure point was defined as the point of peak deviator stress just before the specimen sheared to large strains, with negligible change in shear stress. Prashant and Penumadu (2004) presented a method of identifying the onset of localization using the strain information obtained from a true triaxial shear test. They documented the shear bands and defused localizations observed in the specimens sheared from initial hydrostatic stress state corresponding to $\mathrm{OCR}=5$. Similar patterns were observed for the specimens sheared with normally consolidated to heavily overconsolidated initial hydrostatic stress state. During undrained truetriaxial shearing, the onset of strain localization was identified by a sudden change in the variation of the sum of principal strains ultimately reaching large values, and an abrupt change or fluctuation in the evolution of intermediate and minor principal strains. A typical example of the variation of intermediate principal strain is shown in Fig. 3, in which the curves show a sudden change of their slope at the peak shear stress location (failure point). For all the tests performed in this study, the specimens were observed to have localized deformation at and beyond peak deviator stress. Repeated tests stopped just before the failure condition showed no visible signs of localized deformations and the specimens remained prismatic. Hvorslev (1960) observed shear bands and/or post failure bulging in a series of unconfined compression tests on clay specimens. Vardoulakis (1982) explained that these non-uniformities are "bifurcation and post-bifurcation phenomena which are linked by the constitutive properties of the soil, specimen geometry and boundary conditions, and by geometrical and/or material imperfections." Bifurcation was defined as " a critical state in deformation process when deformation does not follow its 'straight ahead' continuation but

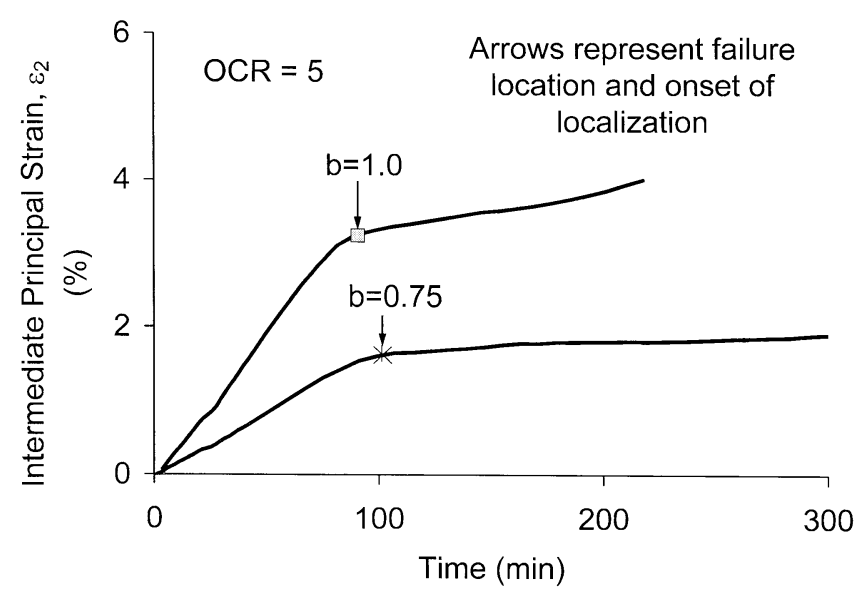

Fig. 3. Identifying the strain localization using intermediate principal strain variation during shearing

turns to an entirely different mode." Under "perfect" boundary conditions, a "perfectly" homogeneous material may undergo non-homogeneous deformation, as various bifurcation modes of deformation develop. Because of this phenomenon, we can say that the single element testing methods with different boundary conditions and specimen shapes may show different postbifurcation shear behavior. Moreover, in the presence of the localized deformation, the strain state cannot be determined accurately using global measurements of deformation, which is the case in most of the single element testing apparatuses used by researchers. In light of these observations and based on the data available to date in literature, one can say that the constitutive equations may only be developed to define the prelocalization behavior of clay, and the failure condition in such a model could be assumed at the onset of localization. However, in most of the previous studies this phenomenon was overlooked and was not considered during the development of various theories, which attempt to define a normalized strength behavior of clay.

\section{UNDRAINED SHEAR BEHAVIOR FROM TRIAXIAL COMPRESSION TESTS AT DIFFERENT 'OCR' VALUES}

Undrained triaxial compression $(b=0)$ tests were performed by shearing the cubical specimens from the initial hydrostatic stress states corresponding to $\mathrm{OCR}=1,1.5$, 2,5 , and 10 . The pre-consolidation stress before shearing was the same for all the specimens, as $p_{0}^{\prime}=275 \mathrm{kPa}$. The shear stress-strain behavior and the effective stress paths observed during these tests are shown in Figs. 4 and 5 respectively. The mean effective stress, $p^{\prime}$, deviator stress, $q$, and the shear strain, $\varepsilon_{\mathrm{q}}$, were calculated from the general invariant expression:

$$
\begin{aligned}
& p^{\prime}=\left(\sigma_{1}^{\prime}+\sigma_{2}^{\prime}+\sigma_{3}^{\prime}\right) / 3 \\
& q=\sqrt{\frac{\left(\sigma_{1}^{\prime}-\sigma_{2}^{\prime}\right)^{2}+\left(\sigma_{2}^{\prime}-\sigma_{3}^{\prime}\right)^{2}+\left(\sigma_{3}^{\prime}-\sigma_{1}^{\prime}\right)^{2}}{2}}
\end{aligned}
$$




$$
\varepsilon_{\mathrm{q}}=\frac{1}{3} \sqrt{2\left\{\left(\varepsilon_{1}-\varepsilon_{2}\right)^{2}+\left(\varepsilon_{2}-\varepsilon_{3}\right)^{2}+\left(\varepsilon_{3}-\varepsilon_{1}\right)^{2}\right\}}
$$

Here, $\sigma_{1}^{\prime}, \sigma_{2}^{\prime}$, and $\sigma_{3}^{\prime}$ were the major, intermediate and minor principal stresses measured along three axes of the cubical specimen, where $\varepsilon_{1}, \varepsilon_{2}$, and $\varepsilon_{3}$ were the corresponding normal strains.

For each OCR value, the observed stress-strain relationship (Fig. 4) was nonlinear from start to failure. With due consideration to classical elasto-plasticity theories, the linear elastic zone of shear deformation (initial yield surface), for overconsolidated clays, may only be defined at small strain values, where the stressstrain relationship can still be assumed linear. As shown in Fig. 6, an approximate limit of the elastic zone (defining yield points) is determined using two approaches (Tavenas et al., 1979; Graham et al., 1983): bi-linear elasto-plasticity and strain energy approach. In the first approach (Fig. 6(a)), the shear stress-strain relationship at small shear strain levels $\left(\varepsilon_{\mathrm{q}}<1.5 \%\right)$ is assumed to be bi-linear. In the other approach (Fig. 6(b)), at the same shear strain levels, the relationship between the length of the stress space vector (LSSV) and the strain energy

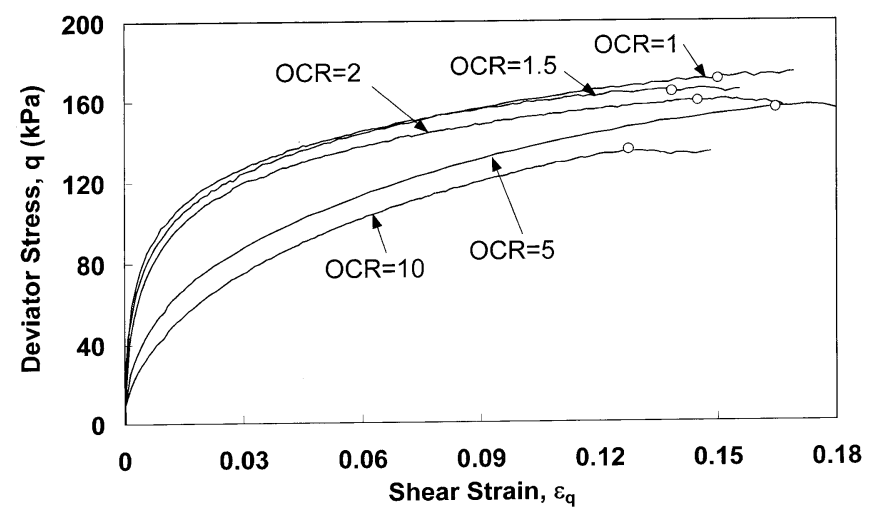

Fig. 4. Shear stress-strain behavior from undrained compression tests $(b=0)$ at various OCR values absorbed by the specimen for deformation $(W)$ is assumed to be bilinear. In these bi-linear relationships, the two lines represent the pre-yield and post-yield behavior, and their intersection point the yield point. Table 2 summarizes the $q$ and $p^{\prime}$ values corresponding to the yield points determined using two approaches, which shows the identical results obtained from both the approaches. The non-linearity in shear stress-strain and LSSV- $W$ relationships suggests that, to some extent, plastic deformation has occurred even before the defined yield points. However, the behavior may be assumed to be predominantly elastic. A probable yield surface in $q-p^{\prime}$ stress space is shown in Fig. 5, by mapping the yield points listed in Table 2 . In $3 \mathrm{D}$ stress space, this surface defines the cross-section of a 3D yield surface of clay in triaxial compression plane. The shape of this yield surface can be visualized as a teardrop, which is similar to the one suggested by Lade (1990) based on the plastic work contours.

Considering the simplicity of formulation and the reasonableness of approximation, most constitutive

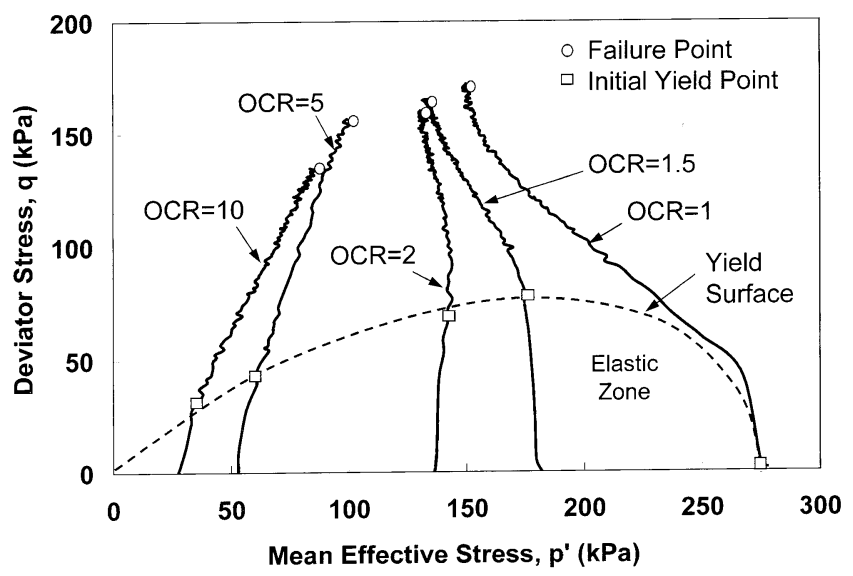

Fig. 5. Effective stress path for undrained compression tests $(b=0)$ at various OCR values (a)

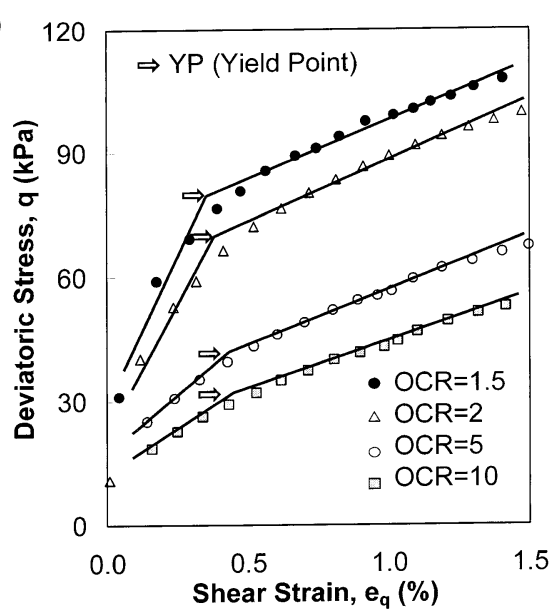

(b)
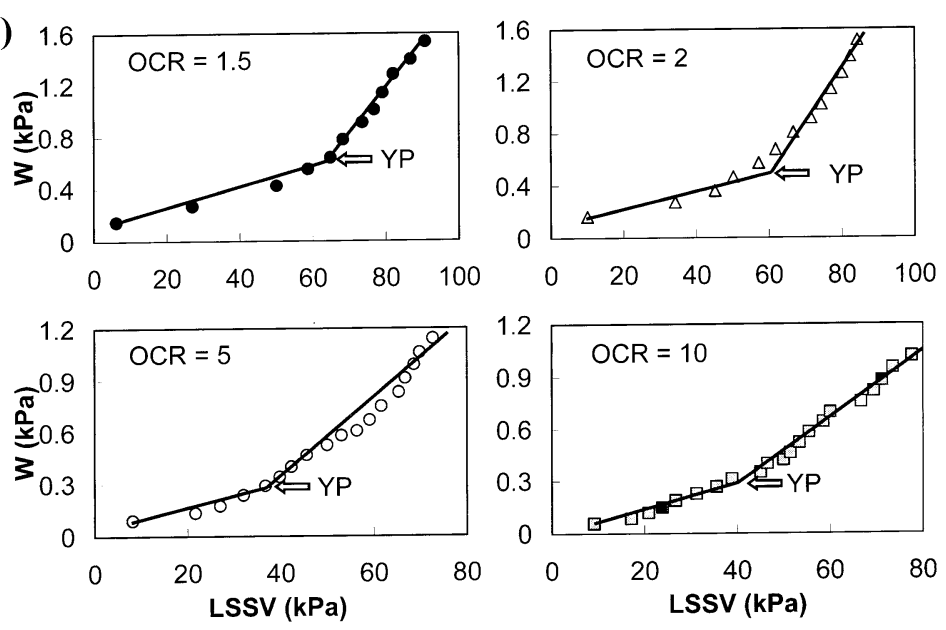

Fig. 6. Determination of yield point using: (a) bi-linear elasto-plasticity and (b) strain energy approach 
Table 2. Point of initial yield during shearing

\begin{tabular}{c|c|c|c|c}
\hline \multirow{2}{*}{ OCR } & \multicolumn{2}{|c|}{$\begin{array}{c}\text { Bi-linear elasto- } \\
\text { plasticity approach }\end{array}$} & \multicolumn{2}{c}{$\begin{array}{c}\text { Strain energy } \\
\text { approach }\end{array}$} \\
\cline { 2 - 5 } & $q(\mathrm{kPa})$ & $p^{\prime}(\mathrm{kPa})$ & $q(\mathrm{kPa})$ & $p^{\prime}(\mathrm{kPa})$ \\
\hline 1.5 & 78 & 175 & 76 & 175 \\
\hline 2 & 68 & 142 & 63 & 141 \\
\hline 5 & 40 & 61 & 40 & 61 \\
\hline 10 & 31 & 35 & 35 & 38 \\
\hline
\end{tabular}

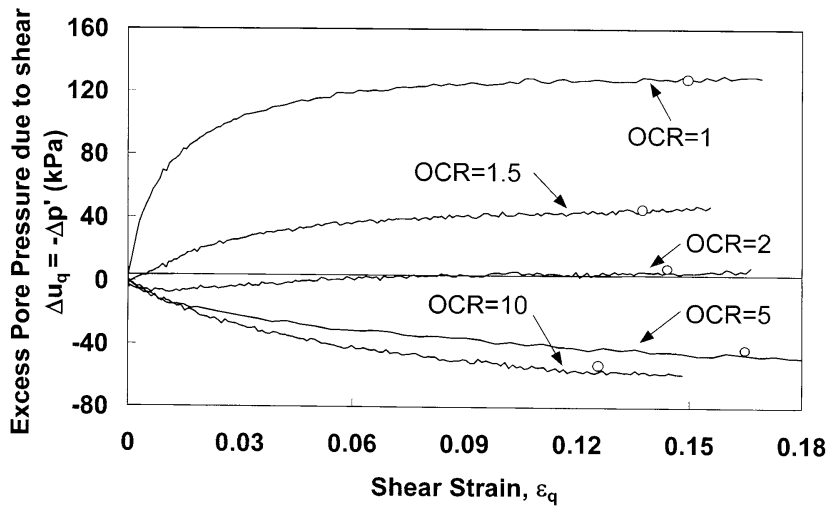

Fig. 7. Excess pore pressure due to shear for undrained compression tests $(b=0)$ at various OCR values

theories assume isotropic elasticity and define the elastic deformation to be uncoupled for volumetric and shear components. In such a case, the elastic volumetric deformation can occur in the specimen, only if there was a change in the mean effective stress. During undrained shear, the volumetric deformation remains zero throughout the shearing; and therefore, in the elastic zone, the mean effective stress should remain constant to maintain zero elastic volumetric deformation. Within the limit of the initial yield surface shown in Fig. 5, the stress paths for the tests at various OCRs can reasonably be assumed to have constant mean effective stress. However, due to a combined influence of the specimen anisotropy and transitional plasticity, a small change in mean effective stress $p^{\prime}$ was observed before reaching the initial yield surface. During elasto-plastic shear deformation (beyond the initial yield surface), the change in $p^{\prime}$ reflects the volumetric response of the clay. The change in mean effective stress, $-\Delta p^{\prime}$, during an undrained test on saturated soil represents a part of the excess pore pressure $\Delta u_{\mathrm{q}}$ that developed due to the applied shear stress. The rest of the pore pressure develops due to the change in mean total stress. Figure 7 shows the evolution of $\Delta u_{\mathrm{q}}$ with shear strain $\varepsilon_{\mathrm{q}}$. The decrease in $p^{\prime}\left(+\Delta u_{\mathrm{q}}\right)$ during undrained shearing indicates the tendency of volumetric compression; whereas, the increase in $p^{\prime}\left(-\Delta u_{\mathrm{q}}\right)$ gives the dilative potential of clay. The specimens sheared from $\mathrm{OCR}=1$ to 2 showed consistent decrease in $p^{\prime}$ during yielding; however, the total change in $p^{\prime}$ through failure, as a result the compressive potential, decreases with the

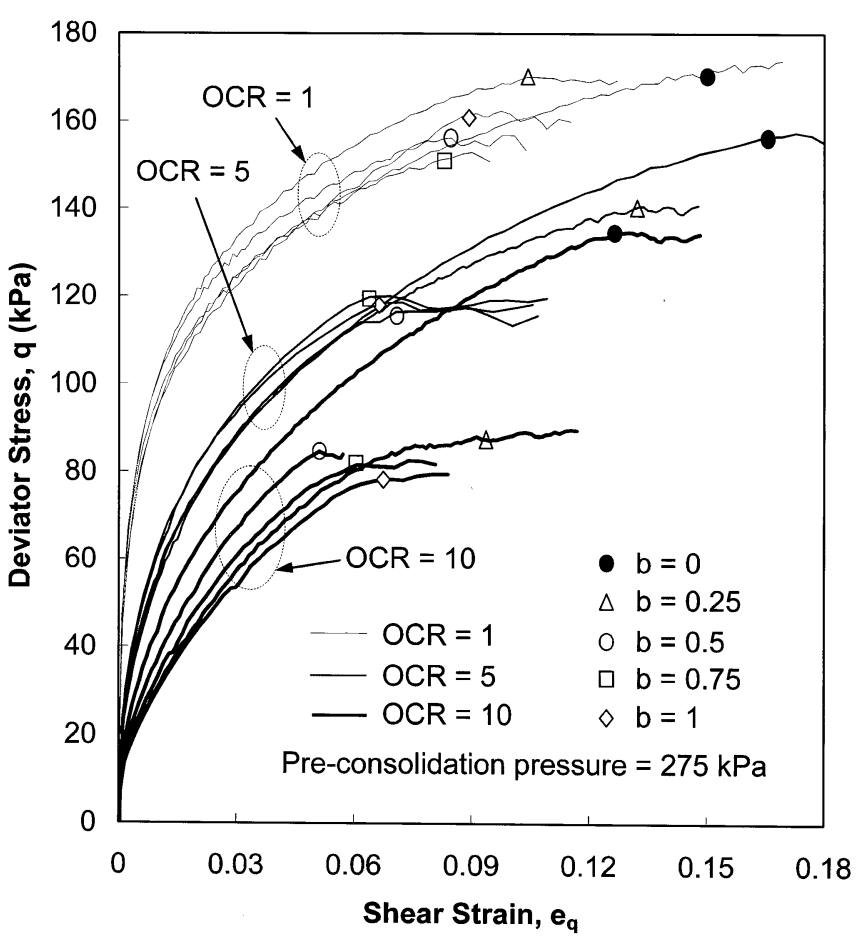

Fig. 8. Influence of intermediate principal stress and anisotropy on the shear stress-strain behavior of clay

increasing OCR. For higher OCR values $(\mathrm{OCR}=5$ and $10), p^{\prime}$ was increasing (dilative) throughout the shearing. From the data presented in Fig. 5, a threshold value of $\mathrm{OCR}=2.2$ may be approximated at which the dilatancy potential can be assumed to be zero.

\section{INFLUENCE OF THE INTERMEDIATE PRINCIPAL STRESS}

To study the influence of intermediate principal stress $\left(\sigma_{2}^{\prime}\right)$ on the clay behavior, a series of constant $b$-value (Eq. (2)) true triaxial undrained tests were performed for $b=0,0.25,0.5,0.75$, and 1 , at various OCR values. Prashant and Penumadu (2004) presented a detailed discussion about the observed influence of $\sigma_{2}^{\prime}$ on the stress-strain, pore pressure and strength behavior using the data obtained from a series of tests performed on moderately overconsolidated $(\mathrm{OCR}=5)$ cubical specimens of kaolin clay. A similar series of flexible boundary true triaxial tests was performed on normally consolidated $(\mathrm{OCR}=1)$ and heavily overconsolidated (OCR $=10$ ) cubical specimens. For all the three series of tests $(\mathrm{OCR}=1,5$, and 10$)$, the pre-consolidation stress was the same as $p_{0}^{\prime}=275 \mathrm{kPa}$. Therefore, the effective confining pressure before shearing for $\mathrm{OCR}=1,5$, and 10 was respectively $275 \mathrm{kPa}, 55 \mathrm{kPa}$, and $28 \mathrm{kPa}$.

Figure 8 compares the undrained shear stress-strain behavior observed at $\mathrm{OCR}=10$ to the observed behavior at $\mathrm{NC}$ and $\mathrm{OCR}=5$ initial stress state. The variation in the shear stress-strain relationship for different $b$-values was more significant at $\mathrm{OCR}=10$ than it was observed at $\mathrm{OCR}=1$ or 5 . The inherent anisotropy induced in the 
specimens during preparation can be used to explain this experimental observation. From the observed consolidation behavior of clay, it was determined that the elastic deformation had more significant influence from the inherent anisotropy than the plastic deformation. Based on this observation, one can also say that a part of the inherent anisotropy remains in the memory of soil during loading-unloading but the significance of its influence depends on the applied effective confining stress. Under this assumption, the increasing mean effective stress would reduce the influence of inherent anisotropy, and consequently reduce the variation in the stress-strain behavior for a change in the $b$-value. On release of the mean effective stress (such as in the case of heavily overconsolidated clay), a part of the anisotropy of the specimen may recover and influence the stress-strain behavior.

The past experimental studies on heavily overconsolidated clays often showed a decrease in the deviatoric stress (during deformation-controlled loading) after the peak showing softening response; however, the decrease was observed to be relatively small under undrained conditions. The use of flexible boundary provides means of reducing the effect of external boundaries on the specimen deformation and poses significantly different boundary conditions than the other testing methods with frictional and/or rigid boundary conditions. In this study, during undrained shearing, the specimens experienced significant strain localizations at the peak deviatoric stress location. After strain localization, the deformation mechanism within the soil specimen is also influenced by the external boundary conditions. As a result, the test data presented in the current study (Fig. 8) using flexible boundary conditions shows only a small amount of softening, and only in few cases.

The triaxial compression tests $(b=0)$ at various OCR values showed failure at the shear strain of $13 \%-15 \%$. The specimens sheared with higher $b$-values failed at lower shear strain values and the shear strain to failure decreased with the increasing overconsolidation. During most of the tests, the specimen sheared at constant shear stress beyond failure; however, the shear stiffness just before the failure was not zero. The stress-strain relationship reached the failure smoothly and showed a sudden change in the slope at failure. With the increasing $b$-value, the significance of sudden failure response increased dramatically. For $b \geq 0.5$, the shear stiffness just before the failure was significantly higher than zero. A typical example of the sudden failure conditions is shown in Fig. 9 using the true triaxial data for $\mathrm{NC}$ specimens sheared with $b=0.25$ and $b=1$. This figure shows that the specimen experienced a sudden loss of the tangent modulus at the failure location, and the prefailure tangent modulus was higher for the specimens sheared with higher $b$-value. The reason behind such failure was probably due to the localization of deformations within the specimens at failure points. The specimen might have reached a higher shear stress level in the absence of localization. Based on these observations, one

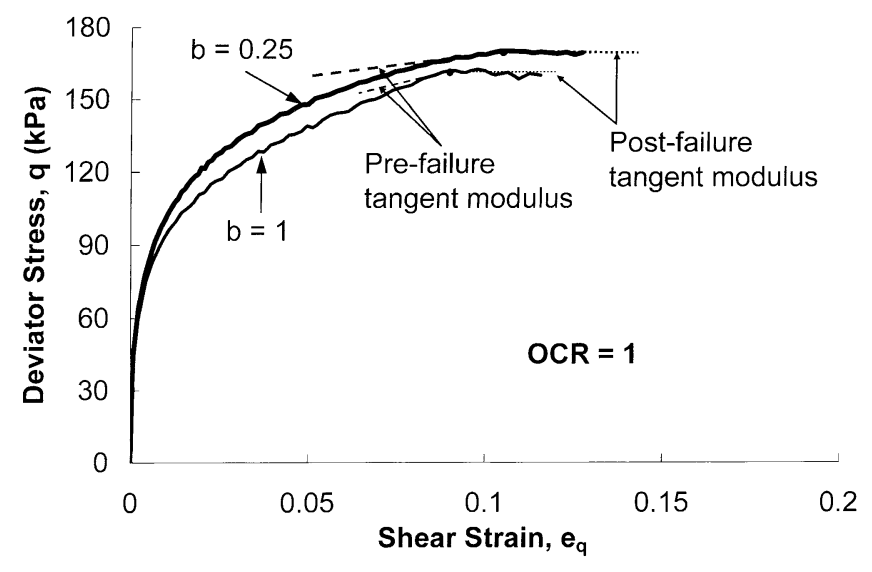

Fig. 9. Pre-failure and post-failure tangent modulus in sudden failure conditions

can say that a constitutive theory developed for such clay should define its formulation of material-yielding independent of the failure surface. A reference surface, bounding the ultimate yield surface for zero shear stiffness and/or defining the shear hardening of material, has been commonly used in a variety of elasto-plasticity models; however, these theories do not differentiate between the reference surface and the failure surface. From the experimental observations in this study, the failure surface may be defined as a lower bound for the reference surface (especially in deviatoric plane), and that would ensure the applicability of the definition of failure at peak deviatoric stress.

\section{Pre-failure Yielding and Strain Localization}

The cubical cohesive specimens used in this research were obtained using two-stage slurry consolidation technique which yielded very uniform water content (hence void ratio). The $102 \mathrm{~mm}$ cube specimen was cut into 64 smaller cube samples of $25 \mathrm{~mm}$ length and water content variation was determined spatially. The average water content was found to be $42.1 \%$ with a standard deviation of $0.7 \%$ thus indicating good uniformity of density (homogeneous at macro level) at a length scale that is measurable easily using moisture content. However, it is also true that the clay specimens may have micro-defects such as density variation at micro-level due to non-uniform distribution of various effective particle sizes (single platelet to agglomerates). These microdefects in natural deposited soils may be even more pronounced. It is a known fact that a lower density and higher void ratio cohesive soil will undergo much higher deformations when subjected to the same loading conditions compared to the same clay at smaller void ratio (Roscoe et al., 1958; Schofield and Wroth, 1968). Therefore, the density variation in clay specimens at micro-level causes non-uniform deformations; whereas, the deformation profile at macro-level will appear to be homogeneous due to averaging effect prior to reaching failure state. The shear stress-strain response of clay is measured at macro-level in a laboratory test, which is the 
averaged response of the micro-level deformations. The micro-level non-uniformities cause many weak zones due to high local strains that grow in size as the specimen deforms further. The propagation of weak zones will be stress path dependent. At one stage when they reach a certain magnitude of macro-level deformation, the high strain zones are detected using localized deformation measuring techniques such as digital imaging (Lin, 2003). Eventually, these zones join each other over a finite thickness and cause large amplitude of shear strains in a particular direction depending on the stress path in the form of a shear band. This is where the specimen experiences a sudden change in the global stress-strain response and, in the current paper, is referred to as reaching sudden failure response. If it is possible to make a perfect laboratory specimen with no void ratio variations as micro and macro scale, then the shear stressstrain behavior will reach failure corresponding to a stress state on reference surface. For such idealized situation, the shear stiffness (tangent modulus) will reach a value of zero prior to large plastic flow.

\section{CLAY STRENGTH}

Over the last few decades, researchers have investigated various clays to establish a relationship that can define the shear failure in terms of the three-dimensional stress state and void ratio. Roscoe et al. (1958) derived a relationship for failure surface in $e-q-p^{\prime}$ space using the critical state void ratio concept. This relationship showed that the critical state was reached by the clay at a constant shear stress ratio, $M\left(=q_{\mathrm{f}} / p_{\mathrm{f}}^{\prime}\right)$, which may be different from the peak shear stress ratio or the shear stress ratio at the peak shear stress level (Egan, 1977). Mayne and Swanson (1981) summarized the results from 90 different clay and silt soils reported throughout the geotechnical literature and confirmed the finding of Ladd and Foott (1974) that the normalized strengths $\left(S_{\mathrm{u}} / \sigma_{\mathrm{v} 0}^{\prime}\right)$ are a function of OCR.

$$
\left(S_{\mathrm{u}} / \sigma_{\mathrm{v} 0}^{\prime}\right)_{\mathrm{OC}}=\left(S_{\mathrm{u}} / \sigma_{\mathrm{v} 0}^{\prime}\right)_{\mathrm{NC}} \mathrm{OCR}^{\Lambda_{0}}
$$

Here $\sigma_{v 0}^{\prime}$ is overburden pressure. The parameter $\Lambda_{0}$ is a soil constant, which is determined from hydrostatically/ anisotropically consolidated shear tests. Mayne and Swanson defined the failure as the undrained strength at maximum deviator stress, since the critical state strengths were not reported by the experimentalists who provided the data. This definition of failure is consistent with the definition used in current research after considering the localization issues discussed earlier. The normalized undrained strengths obtained from the compression tests $(b=0)$ conducted at various OCR values in the current study were used to verify the relationship in Eq. (6). Figure 10 shows that the strength data follows this relationship, and provides a constant value of $\Lambda_{0}=0.90$. Based on the Cam-clay theory (Schofield and Wroth, 1968) $\Lambda_{0}$ was referred to the critical state pore pressure ratio and was defined by

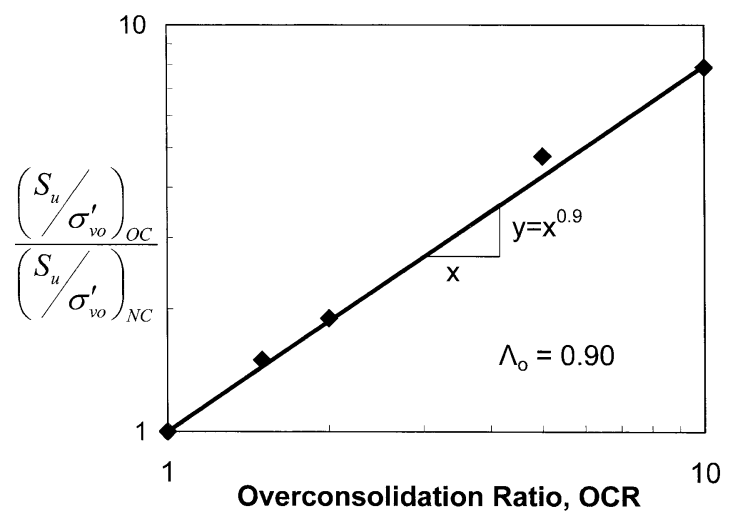

Fig. 10. Variation of normalized undrained strength with OCR

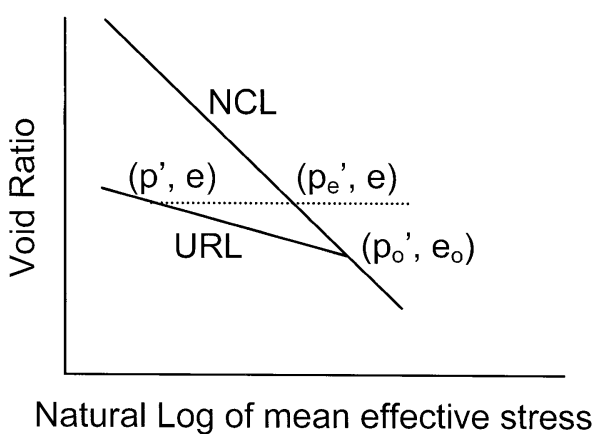

Fig. 11. Isotropic consolidation curve for a typical clay

$$
\Lambda_{0}=1-C_{\mathrm{S}} / C_{\mathrm{C}}
$$

where $C_{\mathrm{C}}$ and $C_{\mathrm{S}}$ were defined as the slopes of normal compression line (NCL) and unloading-reloading line $(\mathrm{URL})$ in $\left(\log p^{\prime}-v\right)$ compression plane. The discrepancy in $\Lambda_{0}$ values obtained experimentally from Eq. (6) and theoretically from Eq. (7) was explained to be due to the assumption of a constant $C_{\mathrm{S}}$ value for a nonlinear URL in compression plane. Since the Eq. (7) was defined to be valid for isotropic frictional materials, the experimental results for anisotropic soils may further add to the discrepancy between the experimental and theoretical values of $\Lambda_{0}$. The value of, $C_{\mathrm{C}}-C_{\mathrm{S}}$, represents the plastic component of the deformation; and therefore, the parameter $\Lambda_{0}=\left(C_{\mathrm{C}}-C_{\mathrm{S}}\right) / C_{\mathrm{C}}$ may be referred to as plasticity ratio.

\section{Failure Surface in Triaxial Plane}

Based on the discussion above, the clay strength may be assumed as a function of void ratio. In stress space, void ratio may be represented by an equivalent mean effective stress, $p_{\mathrm{e}}^{\prime}$ on the NCL. Figure 11 shows the consolidation behavior in compression plane for typical clay. In this figure a clay specimen currently subjected to a mean effective stress $p^{\prime}$ has a void ratio $e$, whereas the mean effective stress and void ratio corresponding to the pre-consolidation stage are $p_{0}^{\prime}$ and $e_{0}$ respectively. The equivalent mean effective stress at current void ratio is denoted by $p_{\mathrm{e}}^{\prime}$. From the equations of NCL and URL: 


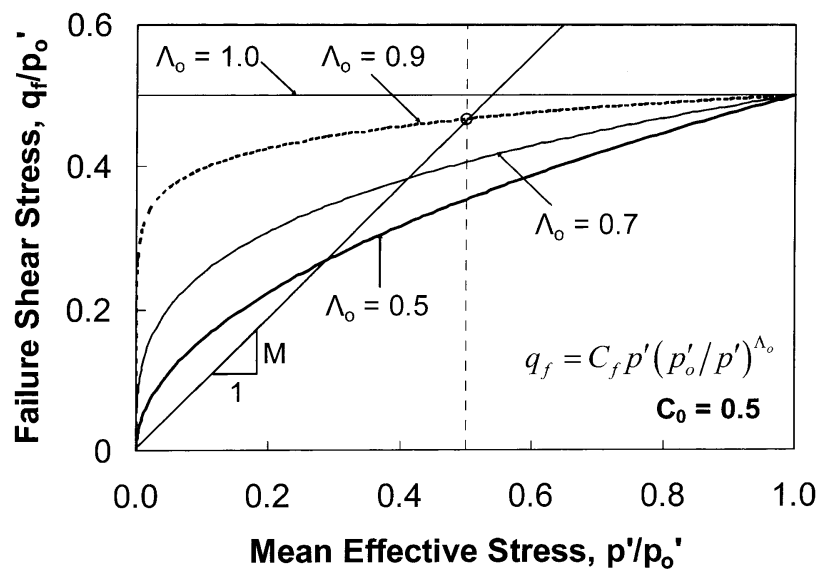

Fig. 12. Failure surface in normalized $q-p^{\prime}$ plane

$$
\begin{aligned}
& C_{\mathrm{C}} \log \left(p_{\mathrm{e}}^{\prime} / p_{0}^{\prime}\right)=\left(e_{0}-e\right)=C_{\mathrm{S}} \log \left(p^{\prime} / p_{0}^{\prime}\right) \\
& p_{\mathrm{e}}=p_{0}^{\prime 1-\left(C_{\mathrm{S}} / C_{\mathrm{C}}\right)} p^{\prime\left(C_{\mathrm{S}} / C_{\mathrm{C}}\right)}=p^{\prime}\left(p_{0}^{\prime} / p^{\prime}\right)^{\Lambda_{0}}
\end{aligned}
$$

The shear strength $q_{\mathrm{f}}$, being related to void ratio, should have a constant relationship with $p_{\mathrm{e}}^{\prime}$. For most clays, this relationship could be assumed linear, which is similar to the relationship suggested by Roscoe et al. (1958) for critical state condition.

$$
q_{\mathrm{f}}=C_{\mathrm{f}} p_{\mathrm{e}}^{\prime}
$$

where, $C_{\mathrm{f}}$ could be a soil constant. Using Eqs. (9) and (10), the failure surface in $q-p^{\prime}$ plane (stress space) can be defined as:

$$
q_{\mathrm{f}}=C_{\mathrm{f}} p^{\prime}\left(p_{0}^{\prime} / p^{\prime}\right)^{\Lambda_{0}}
$$

During an undrained test the $p_{\mathrm{e}}^{\prime}$ remains constant throughout the test, and for $\mathrm{NC}$ clay, the pre-consolidation pressure before shearing $p_{0}^{\prime}$ is equal to $p_{\mathrm{e}}^{\prime}$. Therefore, the shear strength:

$$
q_{\mathrm{fNC}}=C_{\mathrm{f}} p_{\mathrm{e}}^{\prime}=C_{\mathrm{f}} p_{0}^{\prime}
$$

Similarly, for OC clay with initial mean effective stress $p_{i}^{\prime}$ and initial pre-consolidation pressure $p_{0}^{\prime}$ the undrained shear strength may be given by:

$$
q_{\mathrm{fOC}}=C_{\mathrm{f}} p_{\mathrm{e}}^{\prime}=C_{\mathrm{f}} p_{\mathrm{i}}^{\prime}\left(p_{0}^{\prime} / p_{\mathrm{i}}^{\prime}\right)^{\Lambda_{0}}=C_{\mathrm{f}} p_{\mathrm{i}}^{\prime}(\mathrm{OCR})^{\Lambda_{0}}
$$

Equations (12) and (13) can be rearranged to show the normalization of undrained strength in Eq. (6) suggested by Mayne and Swanson (1981):

$$
\frac{q_{\mathrm{fOC}}}{p_{\mathrm{i}}^{\prime}} \mid \frac{q_{\mathrm{fNC}}}{p_{0}^{\prime}}=(\mathrm{OCR})^{\Lambda_{0}}
$$

Figure 12 shows the failure surface defined by Eq. (11) in $q-p^{\prime}$ plane for $\Lambda_{0}=0.5,0.7,0.9$, and 1.0 with a constant value of $C_{\mathrm{f}}=0.5$. The strength of $\mathrm{OC}$ clay relative to the NC clay increases with increasing $\Lambda_{0}$ and reaches its maximum at the theoretical limit of $\Lambda_{0}=1$ when $C_{\mathrm{S}}=0$. The size of the defined failure surface increases with the pre-consolidation stress $p_{0}^{\prime}$, and the $p^{\prime} / p_{0}^{\prime}$ ratio at failure depends on the volumetric response of clay. In the Modified Cam-clay (MCC) model (Roscoe

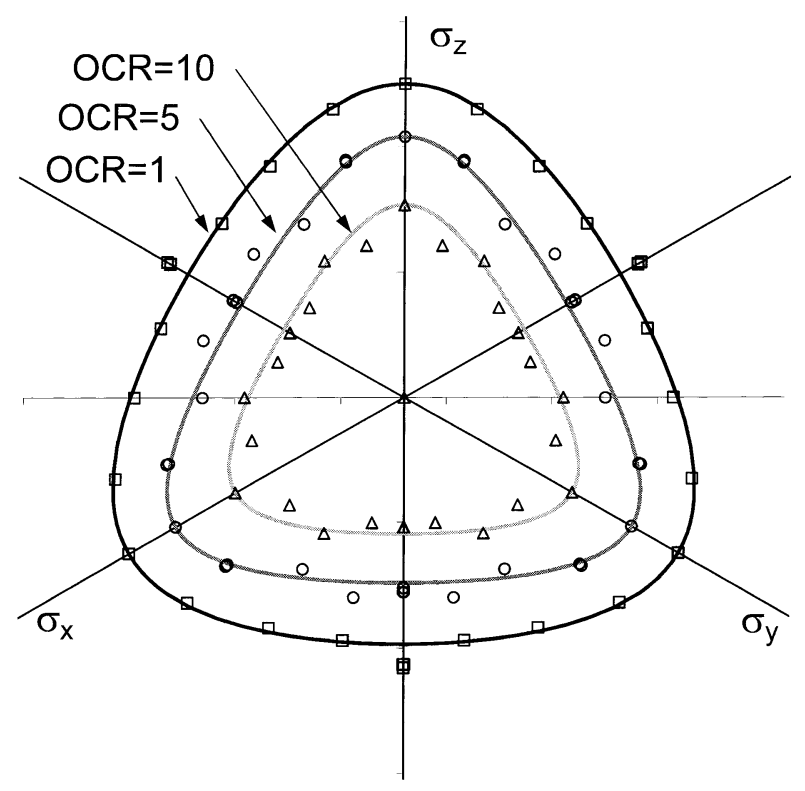

Fig. 13. Failure surface in octahedral plane

and Burland, 1968), soil was assumed to reach critical state at the mean stress ratio $p^{\prime} / p_{0}^{\prime}=2$. The stress state attained at the critical state, during an undrained shear test on normally consolidated (NC) clay, did also correspond to the peak shear stress state and the state of peak shear stress ratio. The peak shear stress ratio at critical state was defined by a soil parameter $M$. To incorporate the current failure surface (Eq. (11)) into the MCC constitutive framework, the parameter $M$ can be related to parameter $C_{\mathrm{f}}$ based on the $p^{\prime} / p_{0}^{\prime}$ ratio at failure:

$$
M=2^{\Lambda_{0}} C_{\mathrm{f}}
$$

The volumetric response at failure of clay may differ from a constant relationship of $\left(p^{\prime} / p_{0}^{\prime}\right)_{\mathrm{f}}=2$ assumed in the MCC model. The current failure surface provides the freedom of $p^{\prime} / p_{0}^{\prime}$ ratio being a soil property and that facilitates better prediction of pore pressure or volumetric strains at failure during shearing of clays.

\section{Failure Surface in Deviatoric Plane}

In the previous section, the failure surface was defined in the triaxial compression plane, which described the influence of overconsolidation and the variation of preconsolidation stress along the hydrostatic stress axis. In order to complete the description of failure surface in 3-D stress space, the strength of clay would now be considered in deviatoric plane (around the hydrostatic axis). For isotropic material, the shear strength may be assumed constant in a deviatoric plane and the failure surface would assume a circular shape in this plane similar to the extended von-Mises failure surface. In the presence of anisotropy, the strength of soil may be described as a function of the relative magnitudes of the principal stresses. Lade (1990) used the third invariant of the stress tensor $\left(I_{3}\right)$ to describe the strength behavior of soil and 
showed the consistency of this assumption over a range of the types of soil. Figure 13 shows the strength data obtained from the series of undrained true triaxial tests performed at three overconsolidation stages $(\mathrm{OCR}=1,5$, and 10). This figure shows that shear failure conditions for the kaolin clay used in current research can be reasonably described using the $I_{3}=k_{1}$ (a constant for a deviatoric plane) failure criterion in the deviatoric plane. The value of $k_{1}$ varies with the mean effective stress at failure; therefore, the data corresponding to one OCR value has been plotted in one deviatoric plane at a constant mean effective stress. The $k_{1}$ value at each deviatoric plane has been calibrated from the triaxial compression test performed at corresponding OCR value. Figure 12 shows that the $I_{3}=k_{1}$ surface presents a reasonable choice of defining failure criteria in deviatoric plane; however, the surface along hydrostatic axis should be defined in agreement with the equation of the failure surface in triaxial plane (Eq. (11)). Considering the shapes in triaxial compression and deviatoric plane a failure surface in 3-D stress space has been derived in APPENDIX, which is defined as

$$
I_{3}=\left(1-\frac{k}{27}\right) p^{\prime 3}, \text { where } k=\left(9-\frac{2 q_{\mathrm{f}}}{p^{\prime}}\right)\left(\frac{q_{\mathrm{f}}}{p^{\prime}}\right)^{2}
$$

Here, $q_{\mathrm{f}} / p^{\prime}$ is the shear strength in triaxial compression $(b=0)$ plane, which is constant for a deviatoric plane and calculated using Eq. (11). Note that the parameter $C_{\mathrm{f}}$ should only be calibrated using triaxial compression tests in order to avoid the complexities of involving the general relationship between $I_{3}$ and $q_{\mathrm{f}} / p^{\prime}$ (Eq. (A10) of APPENDIX) along with Eq. (11) during its determination. The failure surface defined by Eq. (16) may be constrained to a quadrant of the 3-D stress space where all principal stresses are compressive. This would correspond to the widely accepted assumption of no tensile strength in frictional materials such as clay. In this case the $k$-value may be restricted to range from $0 \leq k \leq 27$.

\section{CONCLUSIONS}

In this paper, the influence of overconsolidation and the relative magnitudes of principal stresses on the true triaxial behavior of kaolin clay was evaluated using the data obtained from a series of flexible boundary undrained tests on remolded cubical specimens. To study the influence of inherent anisotropy on the consolidation behavior of clay, the constant rate of strain $K_{0}$ consolidation tests were performed by applying the axial stress along (vertical) and perpendicular (horizontal) to the axis of cross-anisotropy in two different specimens. The experimental observations were discussed with the following conclusions.

a) Assuming the virgin consolidation as elasto-plastic and unloading as elastic deformation, it was observed from the consolidation behavior of the clay that the elastic component of the volumetric deformation, represented by $C_{\mathrm{S}}$, may not be directionally independent for anisotropic clays; however, the plastic component, represented by $C_{\mathrm{C}}-C_{\mathrm{S}}$, may still be assumed constant along all directions.

b) During undrained shearing, the specimens were observed to have localized deformation close to the peak deviatoric stress location, which was therefore considered as the failure location.

c) Based on the shear stress-strain behavior and the undrained stress paths observed at various OCR values, a teardrop shape was found reasonable for the initial yield surface assuming purely elastic behavior within this surface.

d) The influence of inherent anisotropy, reflected through the shear stress-strain behavior observed for different $b$-values, was found to be more significant at lower initial confining stress, showing that the inherent anisotropy in part remains in the memory of clay during loading-unloading but its influence depends on the applied confining pressure.

e) To describe the sudden failure response of clay observed during this study, the authors proposed the use of a different bounding surface for yielding (reference surface) than the failure surface. It was observed that these surfaces may have similar shapes in the triaxial plane but in the deviatoric plane, they have significantly different shapes.

f) Extending the concept of normalization of the undrained strength of clays proposed by Ladd and Foott (1974), the authors have formulated a dynamic failure surface for clays as a function of the effective pre-consolidation pressure. It was observed from the tests performed at each OCR value that the failure surface in the deviatoric plane could be defined using constant third invariant of stress tensor (similar to Lade, 1990), and it was incorporated in the formulation of the proposed failure surface to complete its description in 3-D stress space.

\section{ACKNOWLEDGEMENTS}

Financial Support from National Science Foundation (NSF) through grants CMS-9872618 and CMS-0296111 is gratefully acknowledged. Any opinions, findings, and conclusions or recommendations expressed in this material are those of authors and do not necessarily reflect the views of NSF.

\section{NOTATION}

$b$ : Intermediate principal stress ratio

$B$ : Skempton's pore-pressure parameter

$C_{\mathrm{f}}, \Lambda_{0}$ : Failure surface parameter

$C_{\mathrm{C}}, C_{\mathrm{S}}$ : Compression index, swelling index

$M$ : Critical state shear stress ratio

OCR: Overconsolidation ratio

$p_{0}^{\prime}, \sigma_{\mathrm{v} 0}^{\prime}$ : Pre-consolidation mean effective stress, vertical stress

$p^{\prime}, q, \varepsilon_{\mathrm{q}}$ : Mean effective stress, deviatoric stress, shear strain in invariant form

$S_{\mathrm{u}}$ : Undrained shear strength

$\Delta u, \Delta u_{\mathrm{q}}$ : Excess pore-pressure total, due to shear

$\Delta \varepsilon_{1}, \Delta \varepsilon_{2}, \Delta \varepsilon_{3}$ : Major, intermediate and minor principal strains

$\sigma_{1}^{\prime}, \sigma_{2}^{\prime}, \sigma_{3}^{\prime}$ : Major, intermediate and minor principal effective 
stress

$k_{1}, k$ : Parameters defining the failure surface in deviatoric plane

$\square_{\mathrm{f}}$ : Subscript defining failure point

\section{REFERENCES}

1) Broms, B. B. and Casbarian, A. O. (1965): Effects of rotation of principal stress axes and of the intermediate principal stress on the shear strength, Proc. 6th ICSMFE, Montreal, 1, 179-183.

2) Egan, J. A. (1977): A critical state model for the cyclic loading pore pressure response of soils, $\mathrm{PhD}$ Thesis, Cornell University, Ithaca, New York.

3) Germaine, J. T. (1982): Development of the directional shear cell for measuring cross-anisotropic clay properties, ScD Thesis, Massachusetts Inst. of Tech., Cambridge, Mass.

4) Graham, J., Noonan, M. L. and Lew, K. V. (1983): Yield states and stress-strain relationships in a natural plastic clay, Can. Geotech. J., 20, 502-516.

5) Henkel, D. J. (1959): The relationship between the strength, porewater pressure, and volume-change characteristics of saturated clay, Geotechnique, 9, 119-135.

6) Hvorslev, M. J. (1960): Physical components of the shear strength of saturated clays, ASCE Research Conf. on Shear Strength of Cohesive Soils, University of Colorado, Boulder, Colorado, 69-273.

7) Ladd, C. C. and Foott, R. (1974): New design procedure for stability of soft clays, J. Geotech. Engrg., ASCE, 100 (7), 763-786.

8) Lade, P. V. (1990): Single hardening model with application to NC clay, J. Geotech. Engrg., 116 (3), 394-415.

9) Lade, P. V. and Musante, H. M. (1978): Three-dimensional behavior of remolded clay, ASCE J. Geotech. Engrg. Div., 104 (GT2), 193-209.

10) Lin, H. (2003): Three-dimensional static and dynamic behavior of kaolin clay with controlled microfabric using combined axialtorsional testing, Ph.D. Dissertation, University of Tennessee, Knoxville, USA.

11) Mayne, P. W. and Swanson, P. G. (1981): The critical state pore pressure parameter for consolidated undrained shear tests, Laboratory Shear Strength of Soil, ASTM STP 740 (eds. by Yong, R. N. and Townsend, F. C.), 410-430.

12) Nayak, G. C. and Zienkiewicz, O. C. (1072): Convenient form of stress invariants for plasticity, J. Struc. Div., 98 (ST4), 949-954.

13) Parry, R. H. G. (1960): Triaxial compression and extension tests on remoulded saturated clay, Geotechnique, 10, 166-180.

14) Penumadu, D., Skandarajah, A. and Chameau, J.-L. (1998): Strain-rate effects in pressuremeter testing using a cuboidal shear device: experiments and modeling, Can. Geotech. J., 35, 27-42.

15) Perry, R. H. (1973): Chemical Engineers Handbook, 5th ed.

16) Prashant, A. and Penumadu, D. (2004): Effect of intermediate principal stress on overconsolidated kaolin clay, J. Geotech. Geoenviron. Engrg., ASCE, 130 (3), 284-292.

17) Prevost, J. H. (1981): Nonlinear anisotropic stress-strain-strength behavior of soils, Laboratory Shear Strength of Soil, ASTM STP 740 (eds. by Yong, R. N. and Townsend, F. C.), 431-455.

18) Roscoe, K. H. and Burland, J. B. (1968): On the generalized stressstrain behaviour of 'wet clay', Engineering Plasticity (eds. by Heyman, J. and Leckie, F. A.), Cambridge: Cambridge University Press, 535-609.

19) Roscoe, K. H., Schofield, A. N. and Wroth, C. P. (1958): On yielding of soils, Geotechnique, 8, 22-53.

20) Saada, A. S. and Bianchini, G. F. (1975): The strength of onedimensionally consolidated clays, J. Geotech. Engrg. Div., ASCE, 101 (11), 1151-1164.

21) Schofield, A. N. and Wroth, C. P. (1968): Critical State Soil Mechanics, McGraw-Hill London.

22) Shibata, T. and Karube, D. (1965): Influence of the variation of the intermediate principal stress on the mechanical properties of normally consolidated clays, Proc. 6th ICSMFE, Montreal, 2/48, 359-363.
23) Tavenas, F., Rosiers, Des, J. P., Leroueil, S., Rochelle, La, P. and Roy, M. (1979): The use of strain energy as a yield and creep criterion for overconsolidated clays, Geotechnique, 29 (3), 285-303.

24) Vaid, Y. P. and Campanella, R. G. (1974): Triaxial and plane strain behavior of natural clay, J. SMFD, 100 (GT3), 207-224.

25) Vardoulakis, I. (1982): Stability and bifurcation of soil samples, Constitutive Relations for Soils (eds. by Gudehus, G. et al.), Balkema, Rotterdam, 477-483.

26) Whittle, A. J. and Kavvadas, M. J. (1994): Formulation of MIT-E3 constitutive model for overconsolidated clays, J. Geotech. Engrg., 120 (1), 173-198.

27) Yong, R. N. and McKyes, E. (1971): Yield and failure of clay under triaxial stresses, J. SMFD, 97 (SM1), 159-176.

\section{APPENDIX}

Using the stress invariants in deviatoric plane, Nayak and Zienkiewicz (1972) defined a relationship for the Lode angle $\omega_{\sigma}$ as

$$
\omega_{\sigma}=\frac{1}{3} \cos ^{-1}\left\{\frac{3 \sqrt{3}}{2} \frac{J_{3}^{\prime}}{\left(J_{2}^{\prime}\right)^{3 / 2}}\right\}
$$

where, $0 \leq \omega_{\sigma} \leq \pi / 3$, and $\omega_{\sigma}$ has a constant relationship with intermediate principal stress, as shown in Eq. (A2).

$$
\tan \left(\omega_{\sigma}\right)=\frac{b \sqrt{3}}{2-b}
$$

The deviatoric stress invariants ( $J_{2}^{\prime}$ and $\left.J_{3}^{\prime}\right)$ are related to the invariants of stress tensor, as shown in Eqs. (A3) and (A4).

$$
\begin{aligned}
& J_{3}^{\prime}=\frac{2}{27} I_{1}^{3}+\frac{1}{3} I_{1} I_{2}+I_{3} \\
& J_{2}^{\prime}=\frac{1}{3} I_{1}^{2}+I_{2}
\end{aligned}
$$

The mean effective stress $p^{\prime}$ and deviatoric stress $q$ can be defined in terms of the stress invariants as shown below.

$$
\begin{aligned}
& J_{2}^{\prime}=\frac{q^{2}}{3} \\
& I_{1}=3 p^{\prime}
\end{aligned}
$$

From Eqs. (A3) to (A6),

$$
\begin{aligned}
& I_{2}=J_{2}^{\prime}-\frac{1}{3} I_{1}^{2}=\frac{q^{2}}{3}-3 p^{\prime 2} \\
& J_{3}^{\prime}=p^{\prime} \frac{q^{2}}{3}-p^{\prime 3}+I_{3}
\end{aligned}
$$

Using the relationships Eqs. (A7) and (A8), Eq. (A1) can be defined as

$$
\cos \left(3 \omega_{\sigma}\right)=\frac{27}{2} \frac{p^{\prime} \frac{q^{2}}{3}-p^{\prime 3}+I_{3}}{q^{3}}
$$

At the failure location $q=q_{\mathrm{f}}$; therefore, Eq. (A9) can be written as

$$
\frac{I_{3}}{p^{\prime 3}}=1-\frac{1}{3}\left(\frac{q_{\mathrm{f}}}{p^{\prime}}\right)^{2}+\frac{2}{27}\left(\frac{q_{\mathrm{f}}}{p^{\prime}}\right)^{3} \cos \left(3 \omega_{\sigma}\right)
$$


The Lode angle for triaxial compression $(b=0)$ is $\omega_{\sigma}=0$; therefore, Eq. (A10) can be written as

$$
I_{3}=\left(1-\frac{k}{27}\right) p^{\prime 3}, \text { where } k=\left(9-\frac{2 q_{\mathrm{f}}}{p^{\prime}}\right)\left(\frac{q_{\mathrm{f}}}{p^{\prime}}\right)^{2}
$$

